\title{
Powder Metallurgy Techniques for Titanium Alloys-A Review
}

\author{
Pradeep Kumar Manne ${ }^{1}$, Nutenki Shravan Kumar ${ }^{1}$, Tanya Buddi ${ }^{2}$, A. Anitha Lakshmi ${ }^{3}$, Ram Subbiah ${ }^{2}$ \\ ${ }^{1}$ P.G Student, Dept. of Mechanical Engineering, GRIET, Bachupally, Hyderabad, Telangana, India. \\ ${ }^{2}$ Associate Professor, Dept. of Mechanical Engineering, GRIET, Bachupally, Hyderabad, Telangana, India \\ ${ }^{3}$ Assistant Professor, Dept. of Mechanical Engineering, GRIET, Bachupally, Hyderabad, Telangana, India.
}

\begin{abstract}
Powder metallurgy (PM) is a technique in which materials or components are made from metal powders. In this paper, the overview about titanium alloys and their advantages over engineering applications has been discussed. They are very strong and also possess great mechanical properties and incredible corrosion and wear resistance, and also capable of performing operations at elevated temperatures approximately up to $600^{\circ} \mathrm{C}$. This paper provides various compositions of titanium alloys and various powder metallurgy techniques used for sintering powders of various compositions and their applications. The properties of titanium compounds show the manufacturing of cost effective component. As a result of their fantastic mechanical, physical and organic execution they are finding consistently expanding application in biomedical applications.
\end{abstract}

\section{Introduction}

The high quality, low weight proportion and great erosion opposition of titanium and its composites have achieved a wide scope of uses requiring elevated levels of dependable execution in medical procedure and medication just as in aviation, car, concoction plants and other significant enterprises. In a large number of the building applications, titanium posses less functional or less financially savvy materials. Structures made with the properties of titanium regularly produce financial and progressively solid frameworks and segment [1]. Titanium (Ti-6Al-4V) compound is one which is most broadly used. It has an average machinability and great mechanical properties. For different weight decrease applications in car, aviation and marine gear, this combination has the best in general execution. Ti6Al-4V is likewise known to have different applications in medication [2]. Similar to other metals, at a wide scope of temperatures titanium can crystallize into different precious crystal structures, the greater part of the titanium compounds and alloys of titanium solidify at low temperatures in an obviously adjusted hexagonal close packed structure, called $\alpha$ titanium. However, at high temperatures, the body-focused cubic structure is alluded as $\beta$ titanium. The $\beta$ progress temperature for alloys of titanium is noted as $882 \pm 2^{\circ} \mathrm{C}$. Over a period of time, the capacity to comprehend and control materials has been fundamental to our specialized advancement. Researchers and designers today recognize the significance of utilizing inventive materials for economic and ecological reasons [3]. One such major innovation is powder metallurgy. Powder metallurgy's greatest advantage is control of compositional gradient, Identifying estimation of mechanical properties tentatively permits the material to be simulated by directing auxiliary, thermal or coupled examines to evaluate its suitability for genuine issues.

\section{Powder Metallurgy}

Powder metallurgy is a kind of the solid state process where the graded material is blended in the necessary extent and stacked consistently or in a step wise manner. Squeezing the green conservative at that point packs the material, so the bit got is $80 \%$ thick. The minimized bit is then sintered to deliver $100 \%$ thick segment at the appropriate temperature. The mechanical and tribological property of the completed item relies upon temperature, time of sintering and compaction load.

Jin et al. [7] portrayed how to diminish unwanted leftover pressure impacts coming about because of confuse in the thermal expansion of powder metallurgy creation process. Chenglin et al. [8] examined the production of hydroxyapatite (HAp)-Ti FGM utilizing method of powder metallurgy techniques. Microstructure of (HA)-Ti biomaterial gradually differed, as synthetic piece is finished. This affected both holding quality and hardness of practically evaluated material at various zones. The most extreme durability and bowing quality of unadulterated $\mathrm{Ti}$ areas in practically evaluated material $(29,691 \mathrm{MPa}$ and $971,96 \mathrm{MPa}$, separately) has been a lot higher for human bone quality [9]. This causes this kind of combinations reasonable for inserts which to supplant hard tissue. In 1793 Martin Heinrich Klaproth (17431817) [24-28] who had discovered a few new components and named them as the dad of current diagnostic science, recognized the substance which Gregor thought it was another component. Klaproth called it "titanium," signifying "Earth" in Latin.

\footnotetext{
* Corresponding author: tanyab@griet.ac.in
} 
This powder metallurgy method makes it easy to produce tons of traditional geometrical components, thus large scale manufacturing can be done at cheaper cost. The succession of procedure steps in the Powder Metallurgy process includes blending powder, compacting that blended powder into a die, followed by sintering process in a consolidation chamber. Specific behavior or dimensional accuracy may be implemented in secondary service [4-6].

The steps involved in Powder metallurgy techniques are given as below

(i) Preparation of metal alloy powder, (ii) Blending or mixing, (iii) Compacting, (iv) Sintering, (v) Sizing or impregnation, (vi) Secondary operations.

\subsection{Preparation of metal alloy powder}

Metal powders are the principle constituents of an item made of Powder metallurgy through which properties of the completed item is determined, Powder metallurgy part relies upon size, shape, and surface territory of powder particles. Mechanical methods are the least expensive of the powder generation; these techniques include utilizing mechanical forces, for example, compressive forces, shear to facilitate size reduction of particles from bulk materials.

During processing (milling), impact, steady loss, compression and shear forces are followed up on particles. During impact, striking of one powder molecule against another happens. Steady loss refers to the creation of wear debris because of the rubbing activity between two particles. Shear refers to cutting of particles which results in fracture. The particles are broken into fine particles by compressing activity in pressure power type. Primary goals of processing are Molecule size decrease, Molecule size development, shape change, agglomeration (consolidating of particles) and solid state alloying, mechanical or solid state blending, and alteration of material properties [7-11].

\section{Sequential steps of milling}

In general milling, Changes in the crystal structures of powder particles results in the following sequential events Such as Micro forging, Fracture, Agglomeration and Deagglomeration.

Micro forging: In this process Individual particles or group of particles are compacted repeatedly so that they flatten with very less reduction in mass.

Fracture: In this process, particles deform thus initiate cracks propagation which results in fracture.

Agglomeration: In this process molecule of particles are interlocked due to atomic bonding or Vander Waals forces.

Deagglomeration: In this process Breaking of interlocked particles into fine particles is done.

The diverse powder qualities affected by processing are shape, size, surface, molecule size dispersion, crystalline size, hardness, flowability, compressibility, chemical composition, sinterability, sintered thickness.

Milling: The equipment's generally possess crushers \& mills. Crushing is done for making clay materials such as metal oxides whereas grinding for reactive metals such as titanium, niobium, zirconium and tantalum. Fig 1 shows various types of crushers and mills.

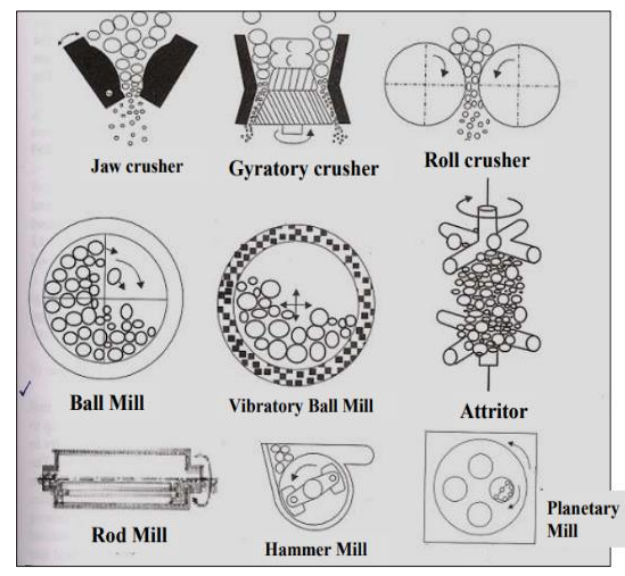

Fig.1. Crushers \& Mills

\subsection{Blending or mixing}

Powders of materials are to be mixed or blended appropriately for getting the necessary properties in the result of sintering. In this procedure the powder and blender are combined finely. Lubricant is additionally utilized to reduce the friction and subsequently getting a better blending. The lubricant to be evacuated of the pass on before submitting it to sintering as the presence of grease may alter the properties of the finished item. Numerous kinds of blenders are being utilized for the assembling of different parts by powder metallurgy method [7].

\subsection{Compacting}

Compacting can be accomplished for molding of the powder in to the necessary shape. In this blended mixture is exposed to pressure, because of the use of weight the gap in the particles gets decreased and the powder gets reduced thus increases adequate strength to withstand ejection and handling. Pressure applied on the powder should be carefully directed as though low pressures are applied on them the part created will be delicate in nature. On the off chance that the pressure applied is more, at that point there might be a twisting of tool at a pressure of 1 to $150 \mathrm{Nm}^{2}$. Compacting is finished through various processes like explosive forming, powder extrusion, isostatic pressing, vibratory compacting, roll compacting or powder rolling.

\subsection{Sintering}

Powder metallurgy process improves the mechanical properties of the manufactured product as a result of appropriately blended reinforcement particles inside the lattice. The connection between the size of the Nanoparticle, amount, surface type and form of reinforcement and the composite properties provided by the powder metallurgy has been established. Various sintering 
processes are used to bind powder particles classified as below.

\subsubsection{Spark Plasma Sintering}

The Spark plasma sintering has the advantage of producing items with a high density other than conventional and micro wave sintering. Powder of the necessary proportions is put in a graphite die in SPS method, where the powder is first compacted followed by sintering, here, pressure and temperature through this process is applied at the same time in the SPS chamber. Increase in temperature rate is very high due to internal heating and can be done in minutes where it takes hours as in traditional processes. Fig 2 shows schematic spark plasma sintering.

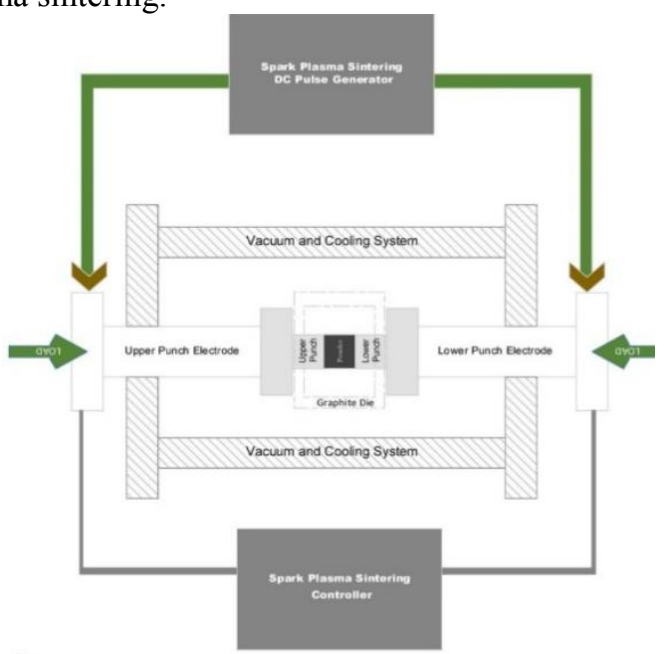

Fig.2. Spark Plasma Sintering

Spark plasma sintering was additionally utilized for the assembling of extra high wear opposition materials for cutting, aspheric glass-focal point forming, sandblasting spouts and machine expelling screws, it is a famous procedure for the production of FGMs, intermetallic mixes, fiber reinforced artistic composite grid (FRCMCs), MMCs and nano items that are hard to sinter utilizing conventional methods. This method for SPS is helpful to the creation of numerous cutting edge mixes. The SPS procedure is practically identical from the hot squeezing process; the main distinction is being the adjustment in the way heat is delivered and provided to the material should have been sintered. The green compact is kept in a graphite die, during this procedure green compact is subjected to curve electrical pulse delivered by pulse electrical release and outside pressure. The warming rate and the external pressure applied separately held as $100-10000^{\circ} \mathrm{C}$ moment and $20-3000$ $\mathrm{N} / \mathrm{m}^{2}$. Porosity can be managed right now get desirable properties. It is an extremely quick procedure consequently the composite densification is high though the disposal of coarsening that happens in ordinary densification process. This procedure in this manner advances the better mechanical properties.

\subsubsection{Selective Laser Sintering (SLS):}

Selective laser sintering is the method of combining powder material to form solid parts through heat and pressure application. The material used in this process may be nylon, polystyrene, and thermoplastic. SLS is a most flexible technique capable of generating complex shapes directly from the CAD model, having high accuracy. SLS process can handle wide range of powder content through layer-by-layer process that is done using electron laser beams.

A sheet of powder made laid down and a $\mathrm{CO}_{2}$ laser is sintered at the points chosen on the model's 2D crosssection (XY-Plane). The platform progressively descends ( $Z$ Plane) according to the layer height specified. The accuracy of this method is between $+/-0.3 \%$ (min. $+/-0.3$ $\mathrm{mm}$ ), minimum layer thickness is $0.08 \mathrm{~mm}$ and the overall sample size is $700 * 380 * 580 \mathrm{~mm}$. Fig. 3 represents the SLS

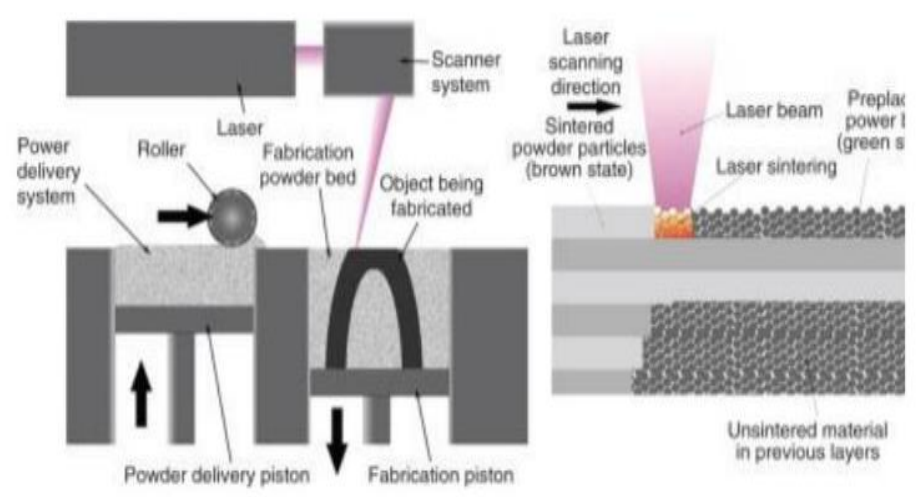

technique of PBF.

Fig.3. Selective Laser Sintering

This approach is ideally suitable for biomedical applications such as pre-operative preparation, tissue engineering prosthetics and bone scaffolds [17-19]. So it has some benefits, which are described below. This PBF process is rapid and accurate, surface of smoother quality is obtained. no need of mould or other tools with minimal waste of material.

\subsubsection{Hot Isostatic Pressing (HIP):}

Materials are manufactured via two processes in the hot isostatic pressing method, one is casting and the other process is of powder metallurgy. These materials mechanical operation is a function of auxiliary, dispersion and porosity that imparts mechanical behavior such as failure resistance, tensile strength, and toughness of fracture. In this process, uniform pressure and high temperature in all directions were applied to the green compact, and argon gas was taken as the fluid medium in a closed vessel to properly consolidate the materials [20, 21]. Due to the simultaneous application of pressure and temperature, it is called ' gas pressure bonding. 'Hot isostatic pressing is widely used to remove defects and to synthesize denser ceramics. In this process mechanical properties are strengthened such as impact resistance and ductility [22]. HIP is regarded as a best technique to enhance mechanical properties of a more number of materials till present time [23]. 


\subsection{Sizing or impregnation}

From the above we comprehended that during the procedure of densification in sintering there might be a variety in size. So in the consequence of sintering the conveyed part is checked by utilizing an master die and weight is applied over the part. This methodology is called sizing. Because of this system the interconnected porosity of the part gets shut and it will be unrealistic to fill the pores with oil or some other metal. So sizing isn't as regularly adopted. A pre machining action is adopted before impregnation.

\subsection{Secondary operations}

A finished segment is to be checked obviously about its properties and different things before it is utilized for the work. The absolute most usually performed tests are elasticity, hardness, compressive quality, porosity, thickness, structure and microstructure.

\section{Titanium Alloys}

\subsection{Ti/apatite}

The practically evaluated metal-earthenware composite, created at $1200^{\circ} \mathrm{C}, 138 \mathrm{MPa}$, by pressure-less sintering. The pure metallic and artistic components are titanium (Ti) and hydroxyapatite (HA), at the parts of the bargains holder. Practically evaluated tests are set up with the 100:0, 75:25, 50:50, 25:75, and 0:100 blending proportions. The barrel shaped examples had a size of 6 $\mathrm{mm}$, and a range of $20 \mathrm{~mm}$. Tests are made utilizing round and hollow carbon die. Tentatively, the ideal thermal charge mapping is obtained. Optical magnifying lens, filtering electron magnifying lens (SEM), vitality dispersive spectrometry (EDX), hardness check portray the properties of all practically reviewed material things. Vickers hardness of HA/Ti is higher than unadulterated microcrystalline $\mathrm{Ti}$ (metal) and diminishes by diminishing the thickness of the layer of HA/Ti. Its significant application is that it is utilized in substitution of human tissue [10].

\section{2 $\mathrm{Ti}^{-\mathrm{ZrO}_{2}}$}

The regular $\mathrm{Ti}_{2} \mathrm{O}$ and $\mathrm{Ti}_{5} \mathrm{O}_{9}$ Gibbs Free energy Capacities were anticipated by the quasi-parabolic law, the thermodynamic steadiness of different oxides in the $\mathrm{Ti}-$ $\mathrm{Zr}-\mathrm{O}$ framework and the existing region of $\mathrm{Ti}$ and $\mathrm{ZrO}_{2}$ was obtained through thermodynamic estimation to build up the blend states of the $\mathrm{Ti}-\mathrm{ZrO}_{2}$ composite. It very well may be concluded, as indicated by the thermodynamic examination which $\mathrm{Ti}$ might respond with $\mathrm{ZrO}_{2}$ in the union procedures of practically evaluated materials (FGMs) from $\mathrm{Ti}-\mathrm{ZrO}_{2}$. In any case, the trial results show that the $\mathrm{Ti} / \mathrm{ZrO}_{2}$ interfaces do not produce a reaction product, and the holding state among $\mathrm{Ti}$ and $\mathrm{ZrO}_{2}$ in the composite is physical $\mathrm{ZrO}_{2}\left(3 \mathrm{~mol}\right.$. percent $\mathrm{Y}_{2} \mathrm{O}_{3}-$ balanced out zirconia) for the most part happens in the readied $\mathrm{Ti}-\mathrm{ZrO}_{2}$ FGMs as a tetragonal advance. Ti's quality applies a critical effect on $\mathrm{ZrO}_{2}$ change from tetragonal to monoclinic procedure. Practically reviewed materials (FGMs) for the Ti-ZrO $\mathrm{rr}_{2}$ framework were set up at $1200-1400^{\circ} \mathrm{C}$ utilizing a powder metallurgical procedure. The warmth permeation model has effectively portrayed the micro structural highlights of $\mathrm{Ti}-\mathrm{ZrO}_{2}$ framework FGMs [11].

\subsection{Ti-TiB 2 :}

For protective layer segments the genuinely gradient materials can be utilized. The high hardness of earthenware production in such materials is joined with the malleability of metals; the $\mathrm{Ti}^{-} \mathrm{TiB}_{2}$ technique is utilized in research. The spark plasma sintering process is utilized as compaction and union methodology. While like conventional hot squeezing, no outer warmth source is required rather the electrically conductive pressure die and sample are passed through pulse direct current. Completely thick materials can be acquired at low sintering temperatures with short holding occasions (minutes), profiting in little grain development. Mechanical and impact tests were done on single layers of metallic fired composites. The ballistic tests were performed on steel backing fixed plates, and tungsten center slugs, $7.62 \mathrm{~mm}$ gauge, were utilized. The ballistic outcomes show an adequate synthesis for the external high-hardness shield plate, which doesn't need to be pure ceramic. so as to check the appropriateness of the flash plasma sintered material, and it was discovered that the SPS-material was the general better protective material [12].

\subsection{TiN/apatite}

The spark plasma sintering methodology (SPS) effectively created in titanium nitride/hydroxyapatite practically reviewed embed (TiN/HAP), and their properties were explored. The practically evaluated materials (FGM) with TiN focus toward one side to HAP at the opposite end were set up by sintering at 1100 and $1200^{\circ} \mathrm{C}$ at $150 \mathrm{MPa}$ pressure. The Brinell hardness was about uniform for the entire arrangement range, around HB 60. Somewhere in the range of 2 to 8 weeks of rodent femur implantation in diaphysis, almost no irritation happened and the new bone created around the example. The deterioration of HAP during the sintering procedure can be forestalled by utilizing TiN rather than $\mathrm{Ti}$, and the powerful sintering of FGM and mechanical properties could be accomplished. These utilizations are inserts for dental use [13].

\subsection{Ti-Tib-TiB 2}

A six-layer functionally graded material (FGM) of Ti$\mathrm{TiB}^{-\mathrm{TiB}_{2}}$ was handily produced in vacuum at $1000^{\circ} \mathrm{C}$ utilizing spark plasma sintering (SPS). Both $\mathrm{B}$ and $\mathrm{TiB}_{2}$ were utilized to combine $\mathrm{TiB}$, and responded with $\mathrm{Ti}$. The alteration of the substance proportion of $\mathrm{B}$ to $\mathrm{TiB}_{2}$ in singular layers could control the measure of combined TiB during sintering by two levels. XRD, SEM, and TEM 
have contemplated the creation and microstructure of the layers in FGM. The orchestrated TiB has agglomerated, needle-like, lengthened morphologies. The substance of agglomerated $\mathrm{TiB}$ expanded and that of the TiB shape diminished with an expansion of 20 to $60 \%$ in the objective TiB volume part. The extended TiB was seen with higher objective TiB volume part in the other two layers whose structure is indistinguishable from the agglomerated TiB. At moderately low sintering temperature and dwelling time, the FGM with Ti on one side to $\mathrm{Ti}-\mathrm{TiB}-\mathrm{TiB}_{2}$ was created by spark plasma sintering. His abilities are in the field of security [14].

\subsection{TiB-Ti:}

A functionally graded material for a four-layer TiB-Ti structure was quickly synthesized utilizing a graphite die with an area-changing cross section using a spark plasma sintering strategy at $1250^{\circ} \mathrm{C}$ and $50 \mathrm{MPa}$. X-ray beam diffraction and checking electron microscopy have described the structure and microstructure of the layers in the practically reviewed material. Each layer's mechanical properties were assessed utilizing the three-point twisting technique and the one-edge, indented bar strategy. The outcomes show that the SPS technique can accomplish a stable reviewed temperature locale. The practically evaluated material from the incorporated $\mathrm{TiB}-\mathrm{Ti}$ framework shows strong, minimized microstructure with ceaseless and split free interfaces. The bowing quality and break strength of each layer in the TiB-Ti framework incorporated practically reviewed material utilizing the pre-planned pass on is a lot higher than that of the relating layer in the material combined utilizing the standard barrel shaped pass on [15].

\section{7 $\mathrm{Ti}_{2} \mathrm{AIN} / \mathrm{TiN}$ :}

A Ti/ALN powder blend with a molar proportion of $2: 1$ has been united with electric current assisted sintering (ECAS) utilizing extraordinarily structured graphite pass on that can offer ascent to a colossal temperature inclination in the reduced sintering bearing, Hence a persistent microstructural advancement was seen during the $\mathrm{Ti}_{2} \mathrm{AlN}$ development. A $\mathrm{Ti}_{2} \mathrm{AlN}-\mathrm{TiN}$ composite was set up at $1200^{\circ} \mathrm{C}, 30 \mathrm{MPa}$, by $\mathrm{Ti}_{2} \mathrm{AlN}$ 's in situ deterioration. The discoveries of the SEM and XRD indicated a constant changeability of the nature of the Ti2AlN and TiN stages the slow conveyance of hardness over the whole composite further proposed that by exploiting the ECAS procedure, a nonstop practically evaluated $\mathrm{Ti}_{2} \mathrm{AlN} / \mathrm{TiN}$ material was gotten simple [16].

\section{8 $\mathrm{Ni}-\mathrm{Ti}$ shape memory alloy:}

Replacing harmed long bones is as yet a significant surgical task. A specific moulding procedure was utilized to deliver a NiTi Shape Memory Compound (SMA), which was worked with reviewed porosity immitating human long bone structure. The external layer of the bone-like reviewed NiTi composite (porosity 14\%) and internal layer (porosity 52\%) were seen as very well co- axial with the interface having a decent metallurgical bond. In addition, the pressure quality and flexible module of the reviewed porosity NiTi SMAs were seen as 360.6 $\mathrm{MPa}$ and 6.7 GPa individually, the NiTi SMAs evaluated porosity displays similar mechanical proficiency as longbones and are viewed as better possibility for long-bone substitution inserts [17].

The titanium amalgams can be seen across wide assortment applications. Despite the fact that they are to a great extent utilized in the aeronautic trade other market areas are presently starting to receive titanium in their different applications, for example, in clinical gadgets, car parts and development designing, for example, aviation motors and airframes. Titanium compounds are additionally utilized in embeds vessels, rocket motor housings, fuel tanks, valve housings, hair springs and blower wheels and so on [29-37].

\section{Conclusion}

> Titanium is a substance which is generally accessible and positions ninth most plentiful component and the fourth richest auxiliary metal situated in the World's outside layer, which surpasses just by iron, aluminum and magnesium. It isn't accessible in unadulterated state and once in a while found in high fixations.

$>$ The quantity and type of alloying elements imparts good mechanical properties and great corrosion and wear resistance to titanium alloy.

$>$ Because of the temperature increment, the issue that ascents with the titanium and its composites is supporting titanium without adjustment in metal phase.

$>$ Because of the great physical and mechanical properties, titanium have numerous advantages for example high softening temperature and lightweight contrasted and steel, which has extended applications.

$>$ Various compositions and different proportions of powders enables different mechanical compatibility properties which are used in many appliances.

\section{References}

1. Titanium alloys for biomedical applications H.J. Rack, J.I. Qazi * School of Materials Science and Engineering, Clemson University, Clemson, SC 29634-0971, USA Available online 12 October 2005

2. Titanium and its Alloy Yassin Mustafa Ahmed ,Khairul Salleh Mohamed Sahari, Mahadzir. Ishak ,Basim Ali Khidhir ISSN (Online): 2319-7064 Impact Factor (2012): 3.358

3. R.K. Joshi, et al., Graphene oxide: the new membrane material, Appl. Mater. Today 1 (1) (2015) 1-12.

4. Torralba JM, Da Costa CE, Velasco F. P/M aluminum matrix composites: An overview. J. Mater. $\quad$ Process.Technol., 2003. https://doi.org/10.1016/S0924-0136 (02) 00234-0. 
5. Casati R, Bonollo F, Dellasega D, Fabrizi A, Timelli $\mathrm{G}$, Tuissi $\mathrm{A}$, et al. Ex situ $\mathrm{Al}-\mathrm{Al}_{2} \mathrm{O}_{3}$ ultrafine grained nanocomposites produced via powder metallurgy. J Alloys Compd 2015.

https://doi.org/10.1016/j.jallcom.2013.10.236.

6. SooryaPrakash K, Gopal PM, Anburose D, Kavimani V. Mechanical, corrosion and wear characteristics of powder metallurgy processed $\mathrm{Ti}$ 6Al-4V

7. Niranjan, steps involved in powder metallurgy process, 06 December 2009, https://www.indiastudychannel.com/resources/978 43-Steps-involved-powder-metallurgyprocess.aspx

8. G. Jin, et al., Properties of multilayered mullite/Mo functionally graded materials fabricated by powder metallurgy processing, Mater. Chem. Phys. 89 (23) (2005) 238-243.

9. C. Chenglin, et al., Hydroxyapatite-Ti functionally graded biomaterial fabricated by powder metallurgy, Mater. Sci. Eng. A 271 (1-2) (1999) 95100.

10. A. Shahrjerdi, F. Mustapha, M. Bayat, S.M. Sapuan, D.L.A. Majid, Fabricationof functionally graded Hydroxyapatite-Titanium by applying optimal sintering procedure and powder metallurgy, (2011) 2258-2267

11. L.D. Teng, F.M. Wang, W.C. Li, Thermodynamics and microstructure of $\mathrm{Ti}-\mathrm{ZrO}_{2}$ metal-ceramic functionally graded materials, Mater. Sci. Eng. A. 293(2000) 130-136

12. W.A. Gooch, B.H.C. Chen, M.S. Burkins, R. Palicka, J.J. Rubin, R.Ravichandran, Development and Ballistic Testing of a Functionally

13. Tummala Suresh Kumar, Kosaraju Satyanarayana, SEM analysis of grid elements in mono-crystalline and poly-crystalline based solar cell, Materials Today: Proceeding, 26 (2), 2020, 3228-3233

14. H. Feng, Q. Meng, Y. Zhou, D. Jia, Spark plasma sintering of functionally graded material in the $\mathrm{Ti}-$ $\mathrm{TiB}_{2}-\mathrm{B}$ system, Mater. Sci. Eng. A. 397 (2005) 9297

15. Z. Zhang, X. Shen, C. Zhang, S. Wei, S. Lee, F. Wang, A new rapid route to in-situ synthesize TiBTi system functionally graded materials using spark plasma sintering method, Mater. Sci. Eng. A. 565 (2013) 326-332

16. Y. Liu, Z. Jin, Electric current assisted sintering of continuous functionally graded $\mathrm{Ti}_{2} \mathrm{AlN} / \mathrm{TiN}$ material, Ceramics International. 38 (2012) 217222

17. D. Zhou, Y. Gao, M. Lai, H. Li, B. Yuan, M. Zhu, Fabrication of NiTi Shape Memory Alloys with Graded Porosity to Imitate Human Long-bone

18. L.E. Murr, A Metallographic Review of 3D Printing/Additive Manufacturing of Metal and Alloy Products and Components, Metallogr. Microstruct.Anal.(2018). https://doi.org/10.1007/s13632-018-0433-6.

19. P. Mercelis, J.P. Kruth, Residual stresses in selective laser sintering and selective laser melting,
Rapid Prototyp. J. (2006). https://doi.org/10.1108/13552540610707013.

20. M. Schmid, A. Amado, K. Wegener, Polymer powders for selective laser sintering (SLS), in: AIP Conf. Proc., 2015. https://doi.org/10.1063/1.4918516.

21. Srinivasa Rao D, Sandhya Rani MN, Sarfaraz Naw az Syed and Suresh Kumar Tummala, E3S Web of Conferences 8701003 (2019).

22. El Kabir T, Joulain A, Gauthier V, Dubois S, Bonneville J, Bertheau D. Hot isostatic pressing synthesis and mechanical properties of $\mathrm{Al} / \mathrm{Al}-\mathrm{Cu}-\mathrm{Fe}$ composite materials. J. Mater Res 2008.https://doi.org/10.1557/jmr.2008.0111.

23. Akbarpour MR, Pouresmaeil A. The influence of CNTs on the microstructure and strength of Al-CNT composites produced by flake powder metallurgy and hot pressing method.DiamRelat Mater 2018. https://doi.org/10.1016/j.diamond.2018.06.021.

24. Tanya Buddi, Nitin Muttil, B Nageswara Rao and Swadesh Kumar Singh, Development of a Soya Based Adhesive in Plywood Manufacturing, Elsevier Materials Today: Proceedings 2, 30273031, 2015.

25. Tanya Buddi, K. Mahesh, Nitin Muttil, B. Nageswara Rao, J. Nagalakshmi, Swadesh Kumar Singh, Characterization Of Plywoods Produced By Various Bio-Adhesives, Elsevier Materials Today: Proceedings, 4, 2, 496-508, 2016

26. Tanya Buddi, B. Nageswara Rao, Swadesh Kumar Singh, Rajesh Purohit \& R. S. Rana, Development and analysis of high density poly ethylene (HDPE) nano $\mathrm{SiO} 2$ and wood powder reinforced polymer matrix hybrid nano composites, Journal of Experimental Nanoscience, 13:sup1, S24-S30, 2018.

27. Tanya Buddi, Swadesh Kumar Singh and B. Nageswara Rao (2018), Optimum Process Parameters for Plywood Manufacturing using Soya Meal Adhesive, Elsevier Materials Today: Proceedings 5, 18739-18744.

28. Archana Nigrawal, Tanya Buddi, RS Rana, R Purohi (2019), Development of Epoxy/Nano SiC composites and their Mechanical Studies", Elsevier Materials Today: Proceedings 18, 4384-4391..

29. AA Lakshmi, CS Rao, Tanya Buddi (2019), "Prediction of Superplasticity of Austenitic Stainless Steel-304 at Hot Working Temperatures", Elsevier Materials Today: Proceedings 18, 28142822.

30. AU Haq, AK Kavit, T Rao, Tanya Buddi, D Baloji, K Satyanarayana, SK Singh (2019), "Evaluation and optimization of material properties of ASS $316 \mathrm{~L}$ at elevated temperatures using Response Surface Methodology", Elsevier Materials Today: Proceedings 18, 4589-4597.

31. D Harshini, A ul Haq, Tanya Buddi, KA Kumar, AA Lakshmi (2019), "Comparative study on mechanical behavior of ASS 316L for low and high temperature applications", Materials Today: Proceedings 19, 767-771. 
32. Tanya Buddi, Anitha Lakshmi Akkireddy, U. S. Jyothi (2020), "Implementation of Outcome-Based Education for a Course: A Case Study", Methodologies and Outcomes of Engineering and Technology Pedagogy, IGI Global, Chapter 13, 272294, DOI: 10.4018/978-1-7998-2245-5.ch013.

33. Tanya Buddi, Swadesh Kumar Singh and B. Nageswara Rao (2020), "Numerical simulations on the bio-based adhesive plywood house structure subjected to self-weight and wind loads", Polymers and Composites Manufacturing, Walter de Gruyter, Chapter 5, 89-108, Series: Advanced Composites, Volume: 11, DOI: 10.1515/9783110655049-005, ISBN 978-3-11-065193-5.

34. B Dharavath, A ul Haq, Tanya Buddi, SK Singh, MT Naik (2020), "Comparative study of ASS 316L on formability at room temperature and super plastic region", Advances in Materials and Processing Technologies, Taylor \& Francis 1-12, DOI: $\quad 10.1080 / 2374068 X .2020 .1728648$, ISSN: 2374-0698.

35. S Kosaraju, SK Singh, Tanya Buddi, A Kalluri, A U1 Haq (2020), "Evaluation and Characterization of ASS316L at sub-zero temperature", Advances in Materials and Processing Technologies, Taylor \& Francis,

$1-11$, DOI: $\quad 10.1080 / 2374068 X .2020 .1728650$, ISSN: 2374-0698.

36. KVD Rajesh, Tanya Buddi, PR Kanth, K Satyanarayana (2020), "Microstructural and corrosion resistance study on plasma arc welded joints of AISI 304 and AISI 316", Advances in Materials and Processing Technologies, Taylor \& Francis, 1-17, DOI: 10.1080/2374068X.2020.1732158, ISSN: 23740698.

37. AA Lakshmi, Tanya Buddi, CS Rao, Fractography analysis and constitutive modeling for dynamic plasticity of austenite stainless steel (ASS 304) at hot-working temperatures, Modern Manufacturing Processes 1st Edition, Elsevier, Chapter 5. 